\title{
Chemical Constituents in E-Cigarette Liquids and Aerosols
}

\author{
Mohd Naeem Mohd Nawi ${ }^{1}$, Sharifah Mazrah Sayed Mohamed Zain ${ }^{2}$, Catrina Ng$^{3}$, \\ Mohd Fairulnizal Md. Noh ${ }^{1}$
}

\begin{abstract}
${ }^{1}$ Nutrition, Metabolism and Cardiovascular Research Centre, Institute for Medical Research (IMR), National Institutes of Health, Ministry of Health Malaysia (MOH), Shah Alam, Selangor, Malaysia

${ }^{2}$ Environmental Health Research Centre, Institute for Medical Research (IMR), National Institutes of Health, Ministry of Health Malaysia (MOH), Shah Alam, Selangor, Malaysia

${ }^{3}$ Perkin Elmer Sdn Bhd, Petaling Jaya, Selangor, Malaysia

Email: naeem@moh.gov.my
\end{abstract}

How to cite this paper: Nawi, M.N.M., Zain, S.M.S.M., Ng, C. and Fairulnizal, M.N.M. (2020) Chemical Constituents in E-cigarette Liquids and Aerosols. Journal of Environmental Protection, 11, 664-681. https://doi.org/10.4236/jep.2020.119040

Received: April 21, 2020

Accepted: September 7, 2020

Published: September 10, 2020

Copyright (c) 2020 by author(s) and Scientific Research Publishing Inc. This work is licensed under the Creative Commons Attribution International License (CC BY 4.0).

http://creativecommons.org/licenses/by/4.0/

(c) (i) Open Access

\begin{abstract}
Electronic cigarettes (e-cigarettes, EC) form an aerosol from the heating element and liquid-containing cartridge. The heating element aerosolizes the refill solutions (e-liquids) when the power source of e-cigarette is pressed. E-liquids consist of combinations of propylene glycol, glycerine, nicotine and flavouring ingredients. Puffing activates the battery-operated heating element in the atomizer and will produce smoke that is similar to conventional cigarette (CC). This study evaluated the chemical composition of e-liquid and aerosol samples available in Malaysia. We analyzed the volatile organic compounds in e-liquids and the aerosols samples from EC using gas chromatography mass spectrometer. Seventy-two EC e-liquids were analyzed through different flavours from more than 60 brands. Samples consisted of 32 nicotine-free $(0 \mathrm{mg})$ and 40 nicotine-containing refill solutions $(3-12 \mathrm{mg})$. Overall, 116 compounds were identified from EC e-liquids. On the other hand, 275 compounds were identified from their resultant aerosol samples. There were 42 compounds found in both e-liquids and aerosols. Seven compounds were only found in e-liquids and 38 compounds were only found in aerosols. Propylene glycol was found in all of the e-liquid and aerosol samples. Glycerin was found in $99 \%$ of the e-liquid and $100 \%$ of aerosol samples. At least $60 \%$ of the EC e-liquids and the resultant aerosol contain piperidine, butanoic acid ethyl ester and nicotine. It was also found that at least 9 out of 35 nicotine free labeled e-liquids contain nicotine. Some of these compounds were known to be detrimental to health and were detected in aerosol although they were not present in e-liquids. While some of the compounds are flavouring ingredients, it is necessary to evaluate its long-term effects on EC users.
\end{abstract}


Keywords

E-Cigarette, Volatile Organic Compounds, Aerosols, E-Liquids, Constituents

\section{Introduction}

Electronic cigarettes (e-cigarettes, EC) form an aerosol from the heating element and liquid-containing cartridge [1]. The heating element aerosolizes the refill solutions (e-liquids) when the power source of EC is pressed. The heating element is made up of metal and can be powered by the battery. E-liquids consist of a mixture of propylene glycol, glycerine, nicotine and flavouring ingredients. Puffing triggers the heating element in the atomizer and will produce smoke that is similar to conventional cigarette (CC). These similarities with CC combined with the same way of smoking have contributed to the rise in the usage of EC all-around the globe [2]. The spread of EC raises huge concern among public health practitioners and great enthusiasm in others, who endorse reducing harm and consider EC as a potential substitute to CC. Starting June 2019, health-care practitioners in USA have recorded 1888 cases of acute lung injury linked to EC usage. The accumulation of cases of EC product use associated lung injury (EVALI) has attracted worldwide attention to the safety of the usage of EC [3]. The common factor among all cases is the use of EC during the 3 months preceding the onset of respiratory disease symptoms. Tetrahydrocannabinol (THC) was found in most of the samples tested by Food Drug Administration (FDA) to date and the majority of patients have admitted consumption of THC-containing products [4].

The analytical results of the products as well as the patients' consumption history suggested that products purchased on the street or informally (family, dealer) were most often involved. Following the trend, selling and usage of EC become widespread in Malaysia market [5]. The prevalence of EC users among Malaysian adults is $3.2 \%$ with an estimated number of 602,122 [6]. Another local population survey found that $27 \%(\mathrm{n}=277)$ respondents agree with the idea that CC is more harmful than EC. On the other hand, $47 \%$ respondents believe that EC deliver less nicotine than CC [7]. EC could act as an introduction to tobacco addiction for a new generation of users. It will also help the renormalization of tobacco-containing products. Discussion with regards to EC is characterized by strong feelings, beliefs and economic considerations which lead to difficulty in getting reliable and credible information [8]. Despite its increasing usage, little is known about the e-liquids chemical constituents. Several recent studies have identified harmful pollutants in aerosol generated by EC [9]. This includes fine and ultrafine particles, reactive oxygen species and toxic compounds associated with flavouring ingredients [10]. It was found that propylene glycol, glycerine, nicotine and various flavouring ingredients are the significant compounds detected in e-liquids [11] [12] [13]. Other researchers have also identi- 
fied aldehydes (acetaldehyde and acrolein) which can be linked with the irritation of respiratory tract [14] [15]. While the aerosols affect the users of EC, it may also impact non users through second hand exposure [16]. The characterization of aerosol is necessary because the aerosolization process was said to be responsible for the formation of aerosol-only compounds. A simple sampling device that can evaluate e-liquids and aerosols for potential differences was developed [17].

At the time of publication, a standard on the manufacturing of e-liquids is not available in Malaysia [5]. Due to this, the quality of e-liquids available in the market is uncertain. This study evaluated the chemical composition of e-liquid and aerosol samples available in Malaysia.

\section{Methods}

\subsection{Study Design and Setting}

We conducted an experimental study that started in January to December 2016. The e-liquids were purchased in June 2016 within all ten (10) districts area in Klang Valley, Selangor, Malaysia. All samples were analyzed within three months of purchase.

\subsection{E-Liquid Sampling}

\subsubsection{E-Liquid Sample Collection}

The study team purchased the e-liquid samples directly from different local shops and night markets. The e-liquids were bought based on the nicotine content varying from 0 to $12 \mathrm{mg} / \mathrm{mL}$. The selection of the e-liquids was based on popular and best-seller brands as claimed by the local dealers.

\subsubsection{E-Liquid Sample Preparation}

The e-liquid samples were prepared by weighing $10 \mathrm{mg}$ of the sample from the e-liquids bottle and added with $1.0 \mathrm{ml}$ of isopropyl alcohol into a $2 \mathrm{~mL}$ vial. The volatile organic compounds (VOCs) that were present in the e-liquid were dissolved entirely and ready to be analyzed.

\subsection{Aerosol Sampling}

\subsubsection{Sampling Technique}

At the time of publication, there was no established smoking machine that was designed for the EC sampling. Aerosol sampling for VOC was based on NIOSH Manual of Analytical Methods No. 2549, Volatile organic compounds (screening) (with modification) [18]. The technique involved using thermal desorption (TD) tubes. This TD tube was a multi-bed sorbent tube containing graphitized carbons and carbon molecular sieve sorbents that trapped VOCs in aerosol samples before analysis [5].

\subsubsection{EC Device}

At the time of publication, there was no established smoking machine that was designed for the EC sampling (Table 1). Aerosol sampling for VOC was based 
Table 1. Characteristics of the EC atomizer and solution tank used for aerosol sampling.

\begin{tabular}{lll}
\hline \multicolumn{1}{c}{ Device part } & \multicolumn{1}{c}{ Atomizer } & \multicolumn{1}{c}{ Solution tank } \\
\hline Name & Elfin Mod & Subtank ${ }^{\mathrm{TM}}$ Mini \\
Manufacturer & Shenzen S-Body Electronics Technology & Shenzen Kanger Technology Co., \\
& Co., Ltd., Shenzhen, China & Ltd., Shenzhen, China \\
& $1-40 \mathrm{~W} ;$ & Atomizer head $1.2 \Omega ;$ \\
Features & Resistance $0.16-2.0 \Omega ;$ & RBA Plus Base $0.5 \Omega / 30 \mathrm{~W}$ coil; \\
& Built-in 18,500 battery & Japanese organic cotton \\
Material & Zinc alloy; & Stainless steel; \\
Size & Stainless steel & Strengthen pyrex glass \\
Capacity & $65 \times 32 \times 22 \mathrm{~mm}$ & $22 \mathrm{~mm}$ diameter $\times 48 \mathrm{~mm}$ length \\
\hline
\end{tabular}

on NIOSH Manual of Analytical Methods No. 2549, Volatile organic compounds (screening) (with modification) [18]. The technique involved using thermal desorption (TD) tubes. This TD tube was a multi-bed sorbent tube containing graphitized carbons and carbon molecular sieve sorbents that trapped VOCs in aerosol samples before analysis [5].

\subsubsection{Sampling Apparatus}

A $50 \mathrm{~mL}$ Hamilton syringe, 1000 series GASTIGHT, (Cat.no 20707) was bought from Sigma-Aldrich Corporation (Missouri, USA). Stainless steel prepacked thermal desorption sorbent tube type Carbotrap 349 was used (Perkin Elmer Inc.). The tubes approximate analyte volatility in the range between $\mathrm{n}-\mathrm{C} 3$ to $\mathrm{n}$-C16 and the typical analytes for NIOSH Method 2549 [18]. Two sizes of latex rubber tubing black from SKC Inc. were used, which are type 1/4-inch ID $\times$ 3/8-inch OD (Cat. No 226-03-004) and type 3/16-inch ID $\times$ 5/16-inch OD (Cat. No 226-03-003) [5].

\subsubsection{Sample Collection}

A simple sampling device was adapted from Herrington and Myers [17] approach using a gas tight syringe connected to a sorbent tube and then to the EC device. In this study, the $50 \mathrm{~mL}$ gas tight syringe was connected to one end of the TD tube using a 3/16-inch ID latex tubing. The other end of the sorbent tube was connected to the EC device using the 1/4-inch ID latex tubing (Figure 1). After the e-liquid was filled into the solution tank, the EC device was activated (LED light up) to heat the e-liquid until aerosol was produced. The EC was observed to light each time the aerosol was drawn through the sorbent tube. The syringe was used to draw $10 \mathrm{~mL}$ of the aerosol generated from the EC device. VOCs that were present in the aerosol was drawn through and trapped by the TD tube. The tubes were then capped securely and ready to be analyzed [5].

\subsection{VOC Analysis}

\subsubsection{Chemicals}

All analytical standards and solvents used were of an analytical grade. Isopropyl alcohol was obtained from Sigma-Aldrich (Missouri, USA). 


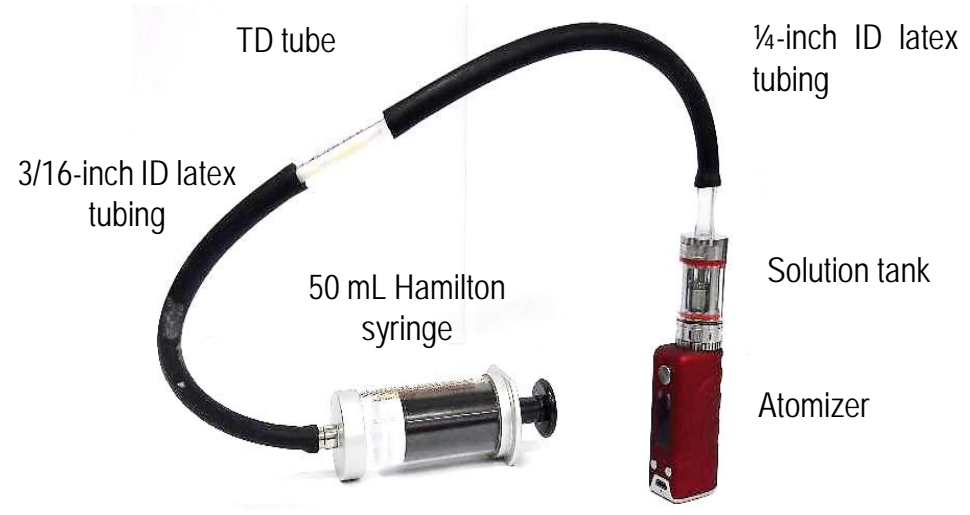

Figure 1. Apparatus set-up for aerosol sampling consists of $50 \mathrm{~mL}$ Hamilton air-tight syringe, latex tubings, TD tube and e-cigarette devices [5].

\subsubsection{Analytical Methods}

VOCs in e-liquid and aerosol were analyzed using Clarus ${ }^{\circledR}$ SQ 8 gas chromatography-mass spectrometer detector (GC-MS, Perkin Elmer Inc.). Chromatographic separation was achieved by Elite-VMS (e-liquid sample) and Elite-VRX column (aerosol sample) $(30 \mathrm{~m}, 0.25 \mathrm{~mm}$ ID, $1.4 \mu \mathrm{m})$. The analytical GC parameters were described in Table 2. Individual peaks were identified by library search against the NIST 11 mass spectral database. The Total Ion Chromatogram (TIC) mode was applied to acquire the maximum number of compounds. For the TIC, a mass range of $15-400 \mathrm{~m} / \mathrm{z}$ was selected. Identification of VOCs was based on mass spectra interpretation and Turbo Mass Software version 6.1.0. The VOCs were classified into different classes such as alcohol, ketone, aldehyde and other classes according to PubChem Database (National Center for Biotechnology Information).

\subsection{Statistical Analysis}

The results for e-liquids and aerosols for each compound were compared by SPSS17.0. Two paired sample t-test was employed as the statistical methods. $\alpha=$ 0.1 was set as the risk level in all statistical analysis, and $\mathrm{p}<0.1$ was considered to be statistically significant.

\subsection{Ethical Considerations}

This study protocol was approved by the Ministry of Health Research and Ethics Committee, Ministry of Health Malaysia with exemption as no ethical issues involved.

\section{Results}

Seventy-two EC e-liquids were analyzed through different flavours from more than 60 brands. Samples consisted of 32 nicotine-free $(0 \mathrm{mg})$ and 40 nicotine-containing refill solutions $(3-12 \mathrm{mg})$. The amount of nicotine, propylene glycol and glycerin were declared in $75 \%$ of the samples. Overall, 116 compounds were identified from EC e-liquids. On the other hand, 275 compounds 
Table 2. Analytical system and parameters used for identification of VOCs in refill solutions and aerosol using gas chromatography-mass spectrometry (GC-MS).

\begin{tabular}{|c|c|}
\hline \multicolumn{2}{|l|}{ Analytical equipment } \\
\hline VOC in e-liquids & Clarus $^{\circledR}$ SQ 8 Gas Chromatograph/Mass Spectrometer (Perkin Elmer Inc.) \\
\hline VOC in aerosol & Clarus $^{\circledR}$ SQ 8 Gas Chromatograph/Mass Spectrometer (Perkin Elmer Inc.) \\
\hline Column (liquid sample) & Elite-VMS (30 m, 0.25 mm ID, $1.4 \mu \mathrm{m})$ (Perkin Elmer Inc.) \\
\hline Column (aerosol sample) & Elite-VRX (30 m, 0.25 mm ID, $1.4 \mu \mathrm{m})$ (Perkin Elmer Inc.) \\
\hline Injection mode & Split 10:1 \\
\hline Injection temperature & $250^{\circ} \mathrm{C}$ \\
\hline Injection volume & $1.0 \mu \mathrm{L}$ \\
\hline Carrier gas & Helium (purity 99.999\%), constant flow \\
\hline Flow rate & $2.0 \mathrm{~mL} / \mathrm{min}$ \\
\hline Oven & $\begin{array}{l}35^{\circ} \mathrm{C} \text { was held for } 1 \text { minute then ramped at rate of } 11^{\circ} \mathrm{C} / \text { minute to } \\
190^{\circ} \mathrm{C} \text {, and then ramped at rate } 15^{\circ} \mathrm{C} / \text { minute of which was further held } \\
\text { for } 3 \text { minutes }\end{array}$ \\
\hline Source temperature & $220^{\circ} \mathrm{C}$ \\
\hline Interface temperature & $250^{\circ} \mathrm{C}$ \\
\hline Run time & $20 \mathrm{~min}$ \\
\hline Acquisition mode & Full scan mode \\
\hline Scan range & $\mathrm{m} / \mathrm{z} 15$ - 400, library search against the NIST 11 mass spectral database \\
\hline Data processing & Turbo Mass Software version 6.1.0 \\
\hline
\end{tabular}

were identified from their resultant aerosol samples. Only compounds that were detected in more than five samples were shown (Tables 3-5).

There were 42 compounds found in both e-liquids and aerosols. Seven compounds were only found in e-liquids and 38 compounds were only found in aerosols. 108 compounds could not be identified. Propylene glycol was found in all of the e-liquid and aerosol samples. Glycerin was found in $99 \%$ of the e-liquid and $100 \%$ of aerosol samples. At least $60 \%$ of the EC e-liquids and the resultant aerosol contain piperidine, butanoic acid ethyl ester and nicotine. It was also found that at least 9 out of 35 nicotine-free labeled e-liquids contain nicotine. Various compounds such as ethyl maltol, vanillin, 1-butanol 3-methyl-acetate, ethyl acetate were found in more than $30 \%$ of the e-liquid and aerosol samples.

There was a significant difference between the amount of e-liquid $(\mathrm{n}=24)$ and aerosol $(n=37)$ samples that contain ethyl acetate. Butanoic acid 2-methyl-ethyl ester, 1,2,3-propanetriol, 1-acetate, 2(3H)-furanone, 5-hexyldihydro-, $2(3 \mathrm{H})$-furanone, 5-heptyldihydro-, maltol, triacetine, menthol, 1,2-propanediol, 2 -acetate, isobutyl acetate and ethyl vanillin were found in more than $10 \%$ of the samples. A significant difference was also observed for e-liquid and aerosol samples that contain compounds such as butanoic acid 3-hydroxy-methyl ester, propanoic acid ethyl ester, 1,4-dioxane-2 6-dimethanol, 1,2-propanediol 1-acetate and 1,2-propanediol 2-acetate. The compounds were detected in e-liquid (4\% $13 \%)$ and aerosol (3\% - 15\%) samples. Compounds such as 2-Propanol, 1, 
Table 3. VOC found in e-liquids.

\begin{tabular}{clccc}
\hline No & \multicolumn{1}{c}{ Compounds } & e-liquid $(\mathrm{n}=72)$ & Aerosol $(\mathbf{n}=72)$ & P Value \\
\hline 1 & 2-Propanol, 1, 1-oxybis- & 14 & 0 & $<0.0001$ \\
2 & Butanoic acid, 3-methylbutyl ester & 12 & 0 & 0.0003 \\
3 & D-Limonene & 10 & 0 & 0.001 \\
4 & 2-Cyclopenten-1-one, 2-hydroxy-3-methyl- & 7 & 0 & $\mathrm{~ns}$ \\
5 & Hexanoic acid, ethyl ester & 6 & 0 & $\mathrm{~ns}$ \\
6 & Linalool & 6 & 0 & $\mathrm{~ns}$ \\
7 & Acetic acid, hexyl ester & 5 & 0 & $\mathrm{~ns}$ \\
\hline
\end{tabular}

$\alpha=0.1$ was set as the risk level in all statistical analysis, and $\mathrm{p}<0.1$ was considered to be statistically significant.

Table 4. VOC found in aerosol samples from EC.

\begin{tabular}{|c|c|c|c|c|}
\hline No & Compounds & $\begin{array}{l}\text { e-liquid } \\
(n=72)\end{array}$ & $\begin{array}{l}\text { Aerosol } \\
(n=72)\end{array}$ & $P$ Value \\
\hline 1 & Acrolein [2-Propenal] & 0 & 57 & $<0.0001$ \\
\hline 2 & Acetic acid & 0 & 45 & $<0.0001$ \\
\hline 3 & Nicotyrine & 0 & 41 & $<0.0001$ \\
\hline 4 & 2-Propen-1-ol & 0 & 39 & $<0.0001$ \\
\hline 5 & a-Nicotine[Pyridine, 2-(1-methyl-2 pyrrolidinyl)- & 0 & 35 & $<0.0001$ \\
\hline 6 & 1-Propen-2-ol, acetate & 0 & 35 & $<0.0001$ \\
\hline 7 & 1,3-Dioxan-5-ol & 0 & 33 & $<0.0001$ \\
\hline 8 & Ethanol & 0 & 30 & $<0.0001$ \\
\hline 9 & 1,3-Dioxane, 2-methyl- & 0 & 27 & $<0.0001$ \\
\hline 10 & Glycidol & 0 & 23 & $<0.0001$ \\
\hline 11 & Acetic formic anhydride & 0 & 19 & $<0.0001$ \\
\hline 12 & 1,2-Propanediol, 3-chloro & 0 & 16 & $<0.0001$ \\
\hline 13 & Acetaldehyde, chloro- & 0 & 14 & $<0.0001$ \\
\hline 14 & Acetone & 0 & 13 & 0.0002 \\
\hline 15 & Butanoic acid, 2,3-dihydroxypropyl ester & 0 & 12 & 0.0003 \\
\hline 16 & 1,2-Propanediol, diformate & 0 & 10 & 0.001 \\
\hline 17 & 1,3-Propanediol, diacetate & 0 & 10 & 0.001 \\
\hline 18 & Acetaldehyde & 0 & 10 & 0.001 \\
\hline 19 & 1H-Pyrazole, 4-chloro- & 0 & 9 & 0.003 \\
\hline 20 & Isopropyl alcohol & 0 & 9 & 0.003 \\
\hline 21 & $\beta$-D-Glucopyranose, 1,6 -anhydro- & 0 & 9 & 0.003 \\
\hline 22 & Oxalacetic acid & 0 & 8 & 0.006 \\
\hline 23 & Isopropyl acetate & 0 & 7 & 0.01 \\
\hline 24 & 2,3-Butanedione & 0 & 7 & 0.01 \\
\hline
\end{tabular}




\section{Continued}

\begin{tabular}{|c|c|c|c|c|}
\hline 25 & 1,3-Dioxane & 0 & 7 & 0.01 \\
\hline 26 & 1,2-Propanediol, 3-methoxy- & 0 & 7 & 0.01 \\
\hline 27 & Methyl glyoxal & 0 & 7 & 0.01 \\
\hline 28 & 1,2,3,4-Butanetriol & 0 & 7 & 0.01 \\
\hline 29 & $\beta$-Citronellol & 0 & 7 & 0.01 \\
\hline 30 & 2-Hexanone & 0 & 6 & 0.03 \\
\hline 31 & Glycidol [1-Propanol, 2,3-epoxy-] & 0 & 6 & 0.03 \\
\hline 32 & 1,3-Dioxolane, 4-methanol & 0 & 6 & 0.03 \\
\hline 33 & 1-Propen-1-ol, acetate & 0 & 6 & 0.03 \\
\hline 34 & Prophyl 2-methylvalerate & 0 & 6 & 0.03 \\
\hline 35 & Benzene & 0 & 5 & 0.06 \\
\hline 36 & Butyl acetate & 0 & 5 & 0.06 \\
\hline 37 & Furan, 2-methyl- & 0 & 5 & 0.06 \\
\hline 38 & Hexanoic acid, propyl ester & 0 & 5 & 0.06 \\
\hline
\end{tabular}

$\alpha=0.1$ was set as the risk level in all statistical analysis, and $\mathrm{p}<0.1$ was considered to be statistically significant.

Table 5. Percentage and compound classification.

\begin{tabular}{|c|c|c|c|c|}
\hline \multirow[t]{2}{*}{ No } & \multirow[t]{2}{*}{ Compounds } & \multicolumn{2}{|c|}{ Percentage (\%) } & \multirow[t]{2}{*}{ Classification } \\
\hline & & $\begin{array}{l}\text { e-liquid } \\
(n=72)\end{array}$ & $\begin{array}{l}\text { Aerosol } \\
(n=72)\end{array}$ & \\
\hline 1 & Propylene glycol & 100.00 & 100.00 & Alcohol \\
\hline 2 & Glycerin & 98.61 & 100.00 & Alcohol \\
\hline 3 & Piperidine & 70.83 & 68.06 & Amine \\
\hline 4 & Nicotine & 62.50 & 68.06 & Pyridine \\
\hline 5 & Ethyl maltol & 44.44 & 55.56 & Ketone \\
\hline 6 & Vanillin & 41.67 & 36.11 & Aldehyde \\
\hline 7 & 1-Butanol, 3-methyl-, acetate & 38.89 & 41.67 & Ester \\
\hline 8 & Ethyl Acetate & 33.33 & 51.39 & Ester \\
\hline 9 & 3-Hexen-1-ol & 27.78 & 15.28 & Alcohol \\
\hline 10 & Butanoic acid, 2-methyl-, ethyl ester & 26.39 & 31.94 & Ester \\
\hline 11 & 1,2,3-Propanetriol, 1-Acetate & 26.39 & 25.00 & Ester \\
\hline 12 & 2(3H)-Furanone, 5-hexyldihydro- & 20.83 & 41.67 & Ketone \\
\hline 13 & 2(3H)-Furanone, 5-heptyldihydro- & 16.67 & 27.78 & Ketone \\
\hline 14 & Maltol & 16.67 & 15.28 & Ketone \\
\hline 15 & Triacetine & 16.67 & 12.50 & Ester \\
\hline 16 & Menthol & 15.28 & 13.89 & Alcohol \\
\hline 17 & Acetic acid, butyl ester & 13.89 & 6.94 & Ester \\
\hline 18 & 1,2,3-Propanetriol, 1,2-Diacetate & 13.89 & 5.56 & Ester \\
\hline
\end{tabular}




\section{Continued}

\begin{tabular}{|c|c|c|c|c|}
\hline 19 & 1,2-Propanediol, 2-Acetate & 12.50 & 33.33 & Ester \\
\hline 20 & Isobutyl acetate & 12.50 & 11.11 & Ester \\
\hline 21 & 2-Propenoic acid, 3-phenyl-, methyl ester & 12.50 & 5.56 & Ester \\
\hline 22 & Ethyl vanillin & 11.11 & 15.28 & Aldehyde \\
\hline 23 & Diphenyl ether & 11.11 & 9.72 & Ether \\
\hline 24 & 1,2-Propanediol, 1-Acetate & 11.11 & 2.78 & Ester \\
\hline 25 & Butanoic acid, 3-methyl-, ethyl ester & 9.72 & 13.89 & Ester \\
\hline 26 & Butanoic acid & 9.72 & 12.50 & Carboxylic Acid \\
\hline 27 & Cyclohexanepropanoic acid, 2-propenyl ester & 9.72 & 6.94 & Ester \\
\hline 28 & Butanoic acid, 3-methyl-,3-methylbuthyl ester & 9.72 & 5.56 & Ester \\
\hline 29 & 6-Octen-1-ol, 3,7-dimethyl- & 9.72 & 1.39 & Terpenoid \\
\hline 30 & Hexanoic acid, 2-propenyl ester & 9.72 & 2.78 & Ester \\
\hline 31 & Acetoin & 8.33 & 1.39 & Ketone \\
\hline 32 & 2(3H)-Furanone, 5-butyldihydro- & 6.94 & 16.67 & Ketone \\
\hline 33 & Methyl Anthranilate & 6.94 & 6.94 & Ester \\
\hline 34 & 1,4-Dioxane-2, 6-dimethanol & 5.56 & 30.56 & Alcohol \\
\hline 35 & Propanoic acid, ethyl ester & 5.56 & 19.44 & Ester \\
\hline 36 & 5-Thiazoleethanol, 4-methyl- & 5.56 & 12.50 & Azole \\
\hline 37 & Propanoic acid & 5.56 & 11.11 & Carboxylic Acid \\
\hline 38 & Butanoic acid, 3-hydroxy-, methyl ester & 4.17 & 15.28 & Ester \\
\hline 39 & 1-Propanol, 2-methyl- & 4.17 & 11.11 & Alcohol \\
\hline 40 & Triethyl citrate & 4.17 & 6.94 & Ester \\
\hline 41 & 1,2,3-Propanediol, 1-Acetate & 2.78 & 8.33 & Ester \\
\hline 42 & 1,2,4-Butanetriol, 2-acetate & 2.78 & 6.94 & Ester \\
\hline 43 & 2-Propanol, 1, 1-oxybis- & 19.44 & 0 & Alcohol \\
\hline 44 & Butanoic acid, 3-methylbutyl ester & 16.67 & 0 & Ester \\
\hline 45 & D-Limonene & 13.89 & 0 & Terpenoid \\
\hline 46 & 2-Cyclopenten-1-one, 2-hydroxy-3-methyl- & 9.72 & 0 & Ketone \\
\hline 47 & Hexanoic acid, ethyl ester & 8.33 & 0 & Ester \\
\hline 48 & Linalool & 8.33 & 0 & Terpenoid \\
\hline 49 & Acetic acid, hexyl ester & 6.94 & 0 & Ester \\
\hline 50 & Acrolein [2-Propenal] & 0 & 79.17 & Aldehyde \\
\hline 51 & Acetic acid & 0 & 62.50 & Carboxylic Acid \\
\hline 52 & Nicotyrine & 0 & 56.94 & Pyridine \\
\hline 53 & 2-Propen-1-ol & 0 & 54.17 & Alcohol \\
\hline 54 & $\begin{array}{l}\text { a-Nicotine[Pyridine,2-(1-methyl-2 } \\
\text { pyrrolidinyl)- }\end{array}$ & 0 & 48.61 & Pyridine \\
\hline 55 & 1-Propen-2-ol, acetate & 0 & 48.61 & Ester \\
\hline
\end{tabular}




\section{Continued}

\begin{tabular}{|c|c|c|c|c|}
\hline 56 & 1,3-Dioxan-5-ol & 0 & 45.83 & Alcohol \\
\hline 57 & Ethanol & 0 & 41.67 & Alcohol \\
\hline 58 & 1,3-Dioxane, 2-methyl- & 0 & 37.50 & Aldehyde \\
\hline 59 & Glycidol & 0 & 31.94 & Ether \\
\hline 60 & Acetic formic anhydride & 0 & 26.39 & Carboxylic anhydride \\
\hline 61 & 1,2-Propanediol, 3-chloro & 0 & 22.22 & Alcohol \\
\hline 62 & Acetaldehyde, chloro- & 0 & 19.44 & Aldehyde \\
\hline 63 & Acetone & 0 & 18.06 & Ketone \\
\hline 64 & Butanoic acid, 2,3-dihydroxypropyl ester & 0 & 16.67 & Ester \\
\hline 65 & 1,2-Propanediol, diformate & 0 & 13.89 & Ester \\
\hline 66 & 1,3-Propanediol, diacetate & 0 & 13.89 & Ester \\
\hline 67 & Acetaldehyde & 0 & 13.89 & Aldehyde \\
\hline 68 & 1H-Pyrazole, 4-chloro- & 0 & 12.50 & Azole \\
\hline 69 & Isopropyl alcohol & 0 & 12.50 & Alcohol \\
\hline 70 & $\beta$-D-Glucopyranose, 1,6 -anhydro- & 0 & 12.50 & Anhydrohexose \\
\hline 71 & Oxalacetic acid & 0 & 11.11 & Carboxylic Acid \\
\hline 72 & Isopropyl acetate & 0 & 9.72 & Ester \\
\hline 73 & 2,3-Butanedione & 0 & 9.72 & Ketone \\
\hline 74 & 1,3-Dioxane & 0 & 9.72 & Ether \\
\hline 75 & 1,2-Propanediol, 3-methoxy- & 0 & 9.72 & Ether \\
\hline 76 & Methyl glyoxal & 0 & 9.72 & Aldehyde \\
\hline 77 & 1,2,3,4-Butanetriol & 0 & 9.72 & Alcohol \\
\hline 78 & $\beta$-Citronellol & 0 & 9.72 & Amine \\
\hline 79 & 2-Hexanone & 0 & 8.33 & Ketone \\
\hline 80 & Glycidol [1-Propanol, 2,3-epoxy-] & 0 & 8.33 & Ether \\
\hline 81 & 1,3-Dioxolane, 4-methanol & 0 & 8.33 & Alcohol \\
\hline 82 & 1-Propen-1-ol, acetate & 0 & 8.33 & Ester \\
\hline 83 & Prophyl 2-methylvalerate & 0 & 8.33 & Ester \\
\hline 84 & Benzene & 0 & 6.94 & Hydrocarbon \\
\hline 85 & Butyl acetate & 0 & 6.94 & Ester \\
\hline 86 & Furan, 2-methyl- & 0 & 6.94 & Furan \\
\hline 87 & Hexanoic acid, propyl ester & 0 & 6.94 & Ester \\
\hline
\end{tabular}

1-oxybis-Butanoic acid, 3-methylbutyl ester and D-Limonene were only detected in e-liquid samples.

The differences between e-liquid and aerosol samples for these three compounds were found to be statistically significant. 2-Cyclopenten-1-one, 2-hydroxy-3-methyl-, Hexanoic acid ethyl ester, Linalool, Acetic acid hexyl ester was the other compounds detected in e-liquid samples. Acrolein was de- 
tected in $79 \%$ of the aerosol samples. Acetic acid, nicotyrine, 2-propen-1-ol were found in more than half of the aerosol samples (54\% - 63\%). $\alpha$-nicotine [pyridine, 2-(1-methyl-2 pyrrolidinyl)-, 1-propen-2-ol, acetate, 1,3-dioxan-5-ol, ethanol, 1,3-dioxane, 2-methyl- and glycidol were found in 30\% to $48 \%$ of aerosol samples. Several compounds such as oxalacetic acid, isopropyl alcohol, acetaldehyde, 1,2-propanediol diformate and acetone were present in $11 \%$ to $18 \%$ of the aerosol samples. Benzene, glycidol [1-propanol 2,3-epoxy], methyl gloxal and isopropyl acetate were few of the compounds detected in $7 \%$ to $10 \%$ of the aerosol samples. Propylene oxide, xylene and styrene were detected in only $1 \%$ of aerosol samples (result not shown).

\section{Discussion}

We identified the compounds in e-liquids and aerosols. Some compounds are present in both e-liquids and aerosols. However, we also found certain compounds that are present in either one of them. Certain compounds detected in were required as main ingredients for the production of e-liquids; propylene glycol and glycerine. Propylene glycol mainly functions as a humectant and is necessary for the production of EC e-liquids. Combination of propylene glycol and glycerin produce aerosols that simulate CC smoke [19]. Heating voltage higher than $3 \mathrm{~V}$ will oxidize the humectants during the aerosol generation process [20]. The oxidation process forms aldehydes found in conventional cigarette smoke [21]. Estimated levels of exposure to propylene glycol and glycerin are a cause of concern [22]. Volunteers subjected to propylene glycol mist for 1 min reported a slight airway obstruction and increased self-rated shortness of breath [23].

Long term exposure to propylene glycol has been linked to the deterioration of multiple allergic symptoms in children [24]. Propylene glycol is a minor respiratory irritant which can cause sore throat or cough [25]. One puff on EC can produce $430-630 \mathrm{mg}$ of propylene glycol per $\mathrm{m}^{3}$ which is enough to irritate the lungs [26]. Ethylene glycol has been used to replace glycerol or propylene glycol in several brands of e-liquids although this was not observed in this study [27]. Ethylene glycol has been linked with various toxicological risks [28]. Glycerin is non-toxic but can form toxic acrolein and glycidol when subjected to heat at higher temperatures [29]. A fellow research group postulated a pathway and by-products formed during thermal degradation of propylene glycol and glycerine [9]. When e-liquids are heated to create aerosol, propylene glycol and glycerine are oxidized and can form potentially hazardous by-products.

Acrolein and acetaldehyde were formed when the coil heats up glycerin in e-liquids. Acrolein is a carbonyl compound that has the potential to be toxic. Inhalation of acrolein can cause severe pulmonary diseases [30]. Acetaldehyde is a probable human carcinogen and listed as carcinogenic [31]. They were formed due to the aerosolization process or from any of the components of the EC device itself. The different voltage used for the EC can lead to higher presence of toxic chemicals [32]. The presence of these two carbonyls in the aerosol was 
consistent with previous observations although formaldehyde was not found in current study [33]. This is in line with the pyrolysis process of propylene glycol. Pyrolysis of propylene glycol is the process that helps in the formation of acetaldehyde and acrolein [17]. Nicotine in e-liquids is extracted from tobacco. It also extracted various impurities such as anabasine, cotinine, beta-nicotyrine and myosmine [34].

Majority of e-liquid manufacturers do not specify health warnings and comprehensive ingredient lists or levels [35]. EC can deliver nicotine in their vapour, with the amount of nicotine differs based on the e-liquid, power of EC and smoking topography [36]. Several studies have reported that e-liquids tested do not contain the same amount of nicotine claimed on the bottle by the manufacturer [37]. Some studies found that e-liquids contain tobacco specific nitrosamines (TSNAs) although this was not observed in this study [36]. TSNAs are derived from tobacco leaves. TSNAs are very potent carcinogens due to their ability to produce DNA adducts, inhibit tumour suppressor genes and activate oncogenes [38]. EC do not contain tobacco so they should not contain TSNAs, which shows that their formation is due to nicotine contaminants [39]. Abramovitz hypothesizes that presence of nicotine degradation products such as beta-nicotyrine is due to accumulation in e-liquids over time but only with exposure to air [40]. Majority of regular users of EC report that they use it with nicotine [41]. Nicotine is highly addictive and those who wish to quit do so because they don't like being dependent on it [42]. Changing to EC does not break the nicotine dependency. Nicotine is considered harmless by some health practitioners while others do not agree [43].

Nicotine stimulates the release of essential neurotransmitters and hormones in central nervous system [44]. In addition, nicotine stimulates the release of catecholamines in the peripheral system. This causes vasoconstriction, increase in heart rate and myocardial contractility [45]. Animal studies suggest that nicotine accelerates atherosclerosis and can fasten growth of cancer cells and the proliferation of endothelial cells [46]. E-liquid flavours are used to recreate the taste of cigarettes or to create a new sensation by giving the aerosol a pleasant taste (fruity, coffee, chocolate or cinnamon flavours) [36]. Compounds such as piperidine, butanoic acid ethyl ester, ethyl maltol, vanillin, 1-butanol 3-methyl-acetate, ethyl acetate come from flavourings added to the e-liquids [47]. The compounds give the e-liquids its distinct flavour.

The compounds are classified as "generally recognized as safe" (GRAS) due to its usage in food production. However, GRAS certification by the Flavor Extracts Manufacturers Association (FEMA) is limited only to ingestion, not inhalation [48]. Butanoic acid ethyl ester is classified as an ester that is used as a flavouring ingredient. It is found in fruits such as apples and gives the e-liquids the fruity flavour. Ethyl maltol is a ketone that is a common flavouring ingredient in confectioneries. It has a sweet smell that is described as caramelized sugar and cooked fruit. Vanillin is classified as an aldehyde and a flavouring ingredient that gives the vanilla smell. 1-butanol 3-methyl-acetate is also an ester that is 
added to e-liquids for odour that is similar to banana and pear. There is a possibility that similar compounds are present in certain types of the flavourings.

Discussion of all flavourings used in e-liquids is impractical given the high diversity of products with unique flavours. Diacetyl (buttery flavour) and acetyl propionyl (caramel or buttery flavour) in $74 \%$ of e-liquids tested [39]. Both compounds were also found in this study (results not shown). Inhalation of diacetyl has been linked to development of bronchiolitis obliterans which is an obstructive respiratory disease [49]. According to Farsalinos, $47.3 \%$ of samples contain diacetyl that is above what is deemed safe for inhalation by NIOSH [39]. Other flavouring ingredients such as vanillin caused alterations in cellular physiology and compromised the ability of airway epithelial cells to maintain homeostasis [50]. The formation of other compounds such as $\alpha$-Nicotine [Pyridine, 2-(1-methyl-2 pyrrolidinyl)-1-Propen-2-ol, acetate 1,3-Dioxan-5-ol, Ethanol, 1,3-Dioxane, 2-methyl-, methyl gloxal and glycidol can be attributed to pyrolysis of flavours and other ingredients added to e-liquids. Methyl gloxal was detected in nine out of 13 aerosol samples and is classified as a mutagen [51]. A research group has postulated that propylene oxide, methyl gloxal, acetaldehyde and formaldehyde were formed during the thermal degradation of propylene glycol [9]. In addition, leaching from other materials used to manufacture the EC could be a potential origin of the compounds [52]. EC often use lithium batteries to power the heating mechanisms, which are susceptible to leak, fires or explosions [53]. Heating mechanisms of ECs are capable of emitting metallic particles such as tin, chromium, lead, tin and cadmium [54]. FDA considers these metals harmful or potentially harmful to human health [53]. EC heating filaments usually is made of nickel and chromium and coated with tin or silver [21] [55]. Tin is a friable metal and can be present in EC aerosol in large amount. It is cytotoxic to human lung fibrolasts and can cause inflammation [55].

Williams also found that nickel levels to be $2-100$ times the amount found in cigarette smoke and can also lead to lung inflammation. The effect of metals from EC is beyond the scope of this article. Health professionals who promoted 'harm reduction' consider that ECs have no adverse long-term health effects. The EC/tobacco industry endorses these views. The usage of EC is spreading to never-smokers and ex-smokers. Many smokers are using both CC and EC or switch instead of quitting and widespread usage of EC will renormalize smoking. Even though EC considered to help in promoting smoking cessation, a recent National Academies of Sciences, Engineering, and Medicine (NASEM) study suggested possible public health harm of EC use [56]. NASEM concluded that although EC usage will increase cessation rate among adults in the short run, the public health benefit is significantly less as even more young EC users switch to use combustible tobacco products in the long run.

The following limitations are acknowledged when interpreting the study results. The study consisted of samples within one state in Malaysia and relied on the information from the sellers which the samples were purchased. There was a lack of standardization in methodologies for aerosol generation used for EC 
analysis. The aerosol sampling method used in this study was manually handled. This might have resulted in loss of samples, inconsistencies and inaccuracy. Due to large number of compounds analyzed, it is also impossible to obtain all the reference standards required for quantification purposes. Hence, this study is only able to report on the presence of the compound (qualitative) instead of the actual amount of the compound (quantitative). Future work would benefit from standardizing laboratory protocols, development of minimally informative detection limits that are needed for risk assessment and quality control experiments. Detailed recommendations on standardization of such protocols are outside of scope of this article.

\section{Conclusion}

E-liquids contain compounds in addition to vendor listed such as propylene glycol, glycerine and nicotine. Some of these compounds were known to be detrimental to health and were detected in aerosol although they were not present in e-liquids. While some of the compounds are flavouring ingredients, it is necessary to evaluate its long-term effects on EC users. Findings of this study can be used by stakeholders such as Ministry of Health Malaysia to develop a standard guideline to regulate the sale and consumption of e-liquids and EC device. Further studies could determine the exact level of the compounds present in e-liquids and aerosols to accurately evaluate its risk assessment to the public and decide whether EC is a public health problem or a useful smoking cessation tool.

\section{Acknowledgements}

The authors would like to gratefully acknowledge the financial support from the Ministry of Health Malaysia and to the Director General of Health Malaysia for the permission to publish. This work was supported by the Ministry of Health Malaysia (grant number NMRR-16-164-28981). This study sponsor had no involvement in the study design, collection, analysis, and interpretation of data and the writing of the manuscript. We would like to extend our sincere gratitude to the Environmental Health Research Centre, Institute for Medical Research (IMR), Malaysia and Perkin Elmer Malaysia, who permitted us to use all the required equipment and necessary materials to complete the task. We thank Dr. Too Chun Lai for providing scientific advice and critically reviewing the manuscript.

\section{Conflicts of Interest}

The authors declare no conflicts of interest regarding the publication of this paper.

\section{References}

[1] Trtchounian, A., Williams, M. and Talbot, P. (2010) Conventional and Electronic Cigarettes (e-Cigarettes) Have Different Smoking Characteristics. Nicotine \& To- 
bacco Research, 12, 905-912. https://doi.org/10.1093/ntr/ntq114

[2] Farsalinos, K., Tsiapras, D., Kyrzopoulos, S., Savvopoulou, M., Avramidou, E. and Vasilopoulou, D. (2012) Acute Effects of Using an Electronic Nicotine-Delivery Device (e-Cigarette) on Myocardial Function: Comparison with the Effects of Regular Cigarettes. European Heart Journal, 33, 203.

[3] Kalininskiy, A., Bach, C.T., Nacca, N.E., Ginsberg, G., Marraffa, J., Navarette, K.A., McGraw, M.D. and Croft, D.P. (2019) E-Cigarette, or Vaping, Product Use Associated Lung Injury (EVALI): Case Series and Diagnostic Approach. The Lancet Respiratory Medicine, 7, 1017-1026. https://doi.org/10.1016/S2213-2600(19)30415-1

[4] Stoebner, S., Faou, A.L., Huteau, M., Gricourt, Y. and Cuvillon, P. (2019) E-Cigarette or Vaping Product Use Associated Lung Injury (EVALI): Health Issues Going beyond Anaesthetic and Surgical Perioperative Procedures. Anaesthesia Critical Care \& Pain Medicine, 38, 563-564. https://doi.org/10.1016/j.accpm.2019.10.012

[5] Zain, S.M.S.M., Khair, S.K.J., Mohamad, N., Noh, M.F.Md. and Radhakrishnan, D.A. (2019) Nicotine Content in Electronic Cigarette Refill Solutions and Its Release in Aerosols. Journal of Environmental Protection, 10, 1317-1332. https://doi.org/10.4236/jep.2019.1010078

[6] National e-Cigarette Survey (NECS) (2016) Prevalence, Pattern and Perception Regarding e-Cigarette and Vape Use among Malaysian Adults. Institute for Public Health, Ministry of Health Malaysia, Kuala Lumpur.

[7] Mohamed Elkalmi, R., Bhagavathul, A.S., Adamu Ya'u, A., et al. (2016) Familiarity, Perception, and Reasons for Electronic-Cigarette Experimentation among the General Public in Malaysia: Preliminary Insight. Journal of Pharmacy and Bioallied Science, 8, 240-247. https://doi.org/10.4103/0975-7406.180768

[8] Pissinger, C. and Døssing, M. (2014) A Systematic Review of Health Effects of Electronic Cigarettes. Preventive Medicine, 69, 248-260. https://doi.org/10.1016/j.ypmed.2014.10.009

[9] Sleiman, M., Logue, J.M., Montesinos, V.N., Russell, M.L., Litter, M.I., Gundel, L.A. and Destaillats, H. (2016) Emissions from Electronic Cigarettes: Key Parameters Affecting the Release of Harmful Chemicals. Environmental Science \& Technology, 50, 9644-9651. https://doi.org/10.1021/acs.est.6b01741

[10] Geiss, O., Bianchi, I., Barahona, F. and Barrero-Moreno, J. (2015) Characterization of Mainstream and Passive Vapours Emitted by Selected Electronic Cigarettes. International Journal of Hygiene and Environmental Health, 218, 169-180. https://doi.org/10.1016/j.ijheh.2014.10.001

[11] Fuoco, F.C., Buonanno, G., Stabile, L. and Vigo, P. (2014) Influential Parameters on Particle Concentration and Size Distribution in the Mainstream of e-Cigarettes. Environmental Pollution, 184, 523-529. https://doi.org/10.1016/j.envpol.2013.10.010

[12] Schober, W., Szendrei, K., Matzen, W., Osiander-Fuchs, H., Heitmann, D., Schettgen, T., Jorres, R.A. and Fromme, H. (2014) Use of Electronic Cigarettes (e-Cigarettes) Impairs Indoor Air Quality and Increases FeNO Levels of e-Cigarette Consumers. International Journal of Hygiene and Environmental Health, 217, 628-637. https://doi.org/10.1016/j.ijheh.2013.11.003

[13] Bekki, K., Uchiyama, S., Ohta, K., Inaba, Y., Nakagome, H. and Kunugita, N. (2014) Carbonyl Compounds Generated from Electronic Cigarettes. International Journal of Environmental Research and Public Health, 11, 11192-11200. https://doi.org/10.3390/ijerph111111192 
[14] Farsalinos, K.E., Voudris, V. and Poulas, K. (2015) E-Cigarettes Generate High Levels of Aldehydes Only in "Dry Puff” Conditions. Addiction, 110, 1352-1356. https://doi.org/10.1111/add.12942

[15] Goniewicz, M.L., Knysak, J., Gawron, M., Kosmider, L., Sobczak, A., Kurek, J., Prokopowicz, A., Jablonska-Czapla, M., RosikDulewska, C., Havel, C., Jacob, P. and Benowitz, N. (2013) Levels of Selected Carcinogens and Toxicants in Vapour from Electronic Cigarettes. Tobacco Control, 23, 133-139. https://doi.org/10.1136/tobaccocontrol-2012-050859

[16] Kosmider, L., Sobczak, A., Fik, M., Knysak, J., Zaciera, M., Kurek, J. and Goniewicz, M.L. (2014) Carbonyl Compounds in Electronic Cigarette Vapors: Effect of Nicotine Solvent and Battery Output Voltage. Nicotine \& Tobacco Research, 16, 1319-1326. https://doi.org/10.1093/ntr/ntu078

[17] Herrington, J.S. and Myers, C. (2015) Electronic Cigarette Solutions and Resultant Aerosol Profiles. Journal of Chromatography A, 1418, 192-199. https://doi.org/10.1016/j.chroma.2015.09.034

[18] National Institute for Occupational Safety and Health (NIOSH, NIOSH): Manual of Analytical Methods. NIOSH, Cincinnati. http://www.cdc.gov/niosh/nmam

[19] Cheng, T. (2014) Chemical Evaluation of Electronic Cigarettes. Tobacco Control, 23, 11-17. https://doi.org/10.1136/tobaccocontrol-2013-051482

[20] Ohta, K., Uchiyama, S., Inaba, Y., et al. (2011) Determination of Carbonyl Compounds Generated from the Electronic Cigarette Using Coupled Silica Cartridges Impregnated with Hydroquinone and 2,4-Dinitrophenylhydrazine. Bunseki Kaga$k u, 60,791-797$. https://doi.org/10.2116/bunsekikagaku.60.791

[21] Williams, M., Villarreal, A., Bozhilov, K., et al. (2013) Metal and Silicate Particles Including Nanoparticles Are Present in Electronic Cigarette Cartomizer Fluid and Aerosol. PLoS ONE, 8, e57987. https://doi.org/10.1371/journal.pone.0057987

[22] Burstyn, I. (2014) Peering through the Mist: Systematic Review of What the Chemistry of Contaminants in Electronic Cigarettes Tells Us about Health Risk. BMC Public Health, 14, Article No. 18. https://doi.org/10.1186/1471-2458-14-18

[23] Wieslander, G., Norback, D. and Lindgren, T. (2001) Experimental Exposure to Propylene Glycol mist in Aviation Emergency Training: Acute Ocular and Respiratory Effects. Occupational and Environmental Medicine, 58, 649-655. https://doi.org/10.1136/oem.58.10.649

[24] Choi, H., Schmidbauer, N., Sundell, J., Hasselgren, M., Spengler, J. and Bornehag, C.G. (2010) Common Household Chemicals and the Allergy Risks in Pre-School Age Children. PLoS ONE, 5, e13423. https://doi.org/10.1371/journal.pone.0013423

[25] Grana, R., Benowitz, N. and Glantz, S.A. (2014) E-Cigarettes: Scientific Review. Circulation, 129, 1972-1986. https://doi.org/10.1161/CIRCULATIONAHA.114.007667

[26] Kienhuis, A.S., Soeteman-Hernandez, L.G., Bos, P.M.J., Cremers, H.W.J.M., Klerx, W.N. and Talhout, R. (2015) Potential Harmful Health Effects of Inhaling Nicotine-Free Shisha-Pen Vapor: A Chemical Risk Assessment of the Main Components Propylene Glycol and Glycerol. Tobacco Induced Diseases, 13, 15. https://doi.org/10.1186/s12971-015-0038-7

[27] Hutzler, C., Paschke, M., Kruschinski, S., Henkler, F., Hahn, J. and Luch, A. (2014) Chemical Hazards Present in Liquids and Vapors of Electronic Cigarettes. Archives of Toxicology, 8, 1295-1308. https://doi.org/10.1007/s00204-014-1294-7

[28] Hess, R., Bartels, M.J. and Pottenger, L.H. (2004) Ethylene Glycol: An Estimate of Tolerable Levels of Exposure Based on a Review of Animal and Human Data. Arc- 
hives of Toxicology, 78, 671-680. https://doi.org/10.1007/s00204-004-0594-8

[29] Hajek, P., Etter, J., Benowitz, N., Eissenberg, T. and Hayden McRobbie, H. (2014) Electronic Cigarettes: Review of Use, Content, Safety, Effects on Smokers and Potential for Harm and Benefit. Addiction, 109, 1801-1810. https://doi.org/10.1111/add.12659

[30] Bein, K. and Leikauf, G.D. (2011) Acrolein-A Pulmonary Hazard. Molecular Nutrition \& Food Research, 55, 1342-1360.

[31] US OSHA (2007) Acetaldehyde. United States Department of Labor, Occupational Safety and Health Administration (OSHA), Washington DC. https://www.osha.gov/dts/chemicalsampling/data/CH 216300.htm

[32] Sutfin, E.L., McCoy, T.P., Morrell, H.E.R., Hoeppner, B.B. and Wolfson, M. (2013) Electronic Cigarette Use by College Students. Drug and Alcohol Dependence, 131, 214-221. https://doi.org/10.1016/j.drugalcdep.2013.05.001

[33] Kosmider, L., Kimber, C.F., Kurek, J., Corcoran, O. and Dawkins, L.E. (2017) Compensatory Puffing with Lower Nicotine Concentration e-Liquids Increases Carbonyl Exposure in e-Cigarette Aerosols. Nicotine \& Tobacco Research, 20, 998-1003. https://doi.org/10.1093/ntr/ntx162

[34] Etter, J.F., Zather, E. and Svensson, S. (2013) Analysis of Refill Liquids for Electronic Cigarettes. Addiction, 108, 1671-1679. https://doi.org/10.1111/add.12235

[35] Kong, A.Y., Derrick, J.C., Abrantes, A.S. and Williams, R.S. (2016) What Is Included with Your Online e-Cigarette Order? An Analysis of e-Cigarette Shipping, Product and Packaging Features. Tobacco Control, 27, 699-702. https://doi.org/10.1136/tobaccocontrol-2016-053061

[36] Zucchet, A. and Schmaltz, G. (2017) Electronic Cigarettes-A Review of the Physiological Health Effects. Facets, 2, 575-609. https://doi.org/10.1139/facets-2017-0014

[37] Pagano, T., Di Francesco, A.G., Smith, S.B., George, J., Wink, G., Rahman, I., et al. (2016) Determination of Nicotine Content and Delivery in Disposable Electronic Cigarettes Available in the United States by Gas Chromatography-Mass Spectrometry. Nicotine \& Tobacco Research, 18, 700-707. https://doi.org/10.1093/ntr/ntv120

[38] Farsalinos, K.E., Kistler, K.A., Gillman, G. and Voudris, V. (2015) Evaluation of Electronic Cigarette Liquids and Aerosol for the Presence of Selected Inhalation Toxins. Nicotine \& Tobacco Research, 17, 168-174. https://doi.org/10.1093/ntr/ntu176

[39] Xue, J., Yang, S. and Seng, S. (2014) Mechanisms of Cancer Induction by Tobacco-Specific NNK and NNN. Cancers, 6, 1138-1156.

https://doi.org/10.3390/cancers6021138

[40] Abramovitz, A., McQueen, A., Martinez, R.E., Williams, B.J. and Sumner, W. (2015) Electronic Cigarettes: The Nicotyrine Hypothesis. Medical Hypotheses, 85, 305-310. https://doi.org/10.1016/j.mehy.2015.06.002

[41] Etter, J.F. and Bullen, C. (2011) Electronic Cigarette: Users Profile, Utilization, Satisfaction and Perceived Efficacy. Addiction, 106, 2017-2028.

https://doi.org/10.1111/j.1360-0443.2011.03505.x

[42] Pisinger, C., Aadahl, M., Toft, U. and Jorgensen, T. (2011) Motives to Quit Smoking and Reasons to Relapse Differ by Socioeconomic Status. Preventive Medicine, 52, 48-52. https://doi.org/10.1016/j.ypmed.2010.10.007

[43] National Center for Chronic Disease Prevention and Health Promotion (2014) Chapter 12 Smoking-Attributable Morbidity, Mortality, and Economic Costs. The Health Consequences of Smoking: 50 Years of Progress: A Report of the Surgeon 
General, 647-680.

[44] Balfour, D.J. (1982) The Effects of Nicotine on Brain Neurotransmitter Systems. Pharmacology \& Therapeutics, 16, 269-282. https://doi.org/10.1016/0163-7258(82)90058-4

[45] Kilaru, S., Frangos, S.G., Chen, A.H., et al. (2001) Nicotine: A Review of Its Role in Atherosclerosis. Journal of the American College of Surgeons, 193, 538-546. https://doi.org/10.1016/S1072-7515(01)01059-6

[46] Condorelli, R.A., La, V.S., Giacone, F., Iacoviello, L., et al. (2013) In Vitro Effects of Nicotine on Sperm Motility and Bio-Functional Flow Cytometry Sperm Parameters. International Journal of Immunopathology and Pharmacology, 26, 739-746. https://doi.org/10.1177/039463201302600317

[47] Leventhal, A.M., Strong, D.R., Kirkpatrick, M.G., et al. (2015) Association of Electronic Cigarette Use with Initiation of Combustible Tobacco Product Smoking in Early Adolescence. JAMA, 314, 700-707. https://doi.org/10.1001/jama.2015.8950

[48] Tierney, P.A., Karpinski, C.D., Brown, J.E., Luo, W. and Pankow, J.F. (2016) Flavour Chemicals in Electronic Cigarette Fluids. Tobacco Control, 25, e10-e15. https://doi.org/10.1136/tobaccocontrol-2014-052175

[49] Shibamoto, T. (2014) Diacetyl: Occurrence, Analysis, and Toxicity. Journal of Agricultural and Food Chemistry, 62, 4048-4053. https://doi.org/10.1021/jf500615u

[50] Sherwood, C.L. and Boitano, S. (2016) Airway Epithelial Cell Exposure to Distinct e-Cigarette Liquid Flavorings Reveals Toxicity Thresholds and Activation of CFTR by the Chocolate Flavoring 2,5-Dimethypyrazine. Respiratory Research, 17, 57. https://doi.org/10.1186/s12931-016-0369-9

[51] Uchiyama, S., Ohta, K., Inaba, Y. and Kunugita, N. (2013) Determination of Carbonyl Compounds Generated from the E-Cigarette Using Coupled Silica Cartridges Impregnated with Hydroquinone and 2,4-Dinitrophenylhydrazine, Followed by High-Performance Liquid Chromatography. Analytical Sciences, 29, 1219-1222. https://doi.org/10.2116/analsci.29.1219

[52] Spencer, A. and Lauterbach, J.H. (2015) Generation of Acetaldehyde and Other Carbonyl Compounds during Vaporization of Glycerol and Propylene Glycol during Puffing of a Popular Style of e-Cigarette. 54th Meeting of the Society of Toxicology, San Diego, 22-26 March 2015, Abstract 188.

[53] Brown, C.J. and Cheng, J.M. (2014) Electronic Cigarettes: Product Characterisation and Design Considerations. Tobacco Control, 23, ii4-ii10. https://doi.org/10.1136/tobaccocontrol-2013-051476

[54] Hess, C.A., Olmedo, P., Navas-Acien, A., Goessler, W., Cohen, J.E. and Rule, A.M. (2017) E-Cigarettes as a Source of Toxic and Potentially Carcinogenic Metals. Environmental Research, 152, 221-225. https://doi.org/10.1016/j.envres.2016.09.026

[55] Williams, M., To, A., Bozhilov, K. and Talbot, P. (2015) Strategies to Reduce Tin and Other Metals in Electronic Cigarette Aerosol. PLoS ONE, 10, e0138933. https://doi.org/10.1371/journal.pone.0138933

[56] The National Academies of Sciences, Engineering, and Medicine (NASEM) (2018) Public Health Consequences of e-Cigarettes. The National Academies Press, Washington DC. 